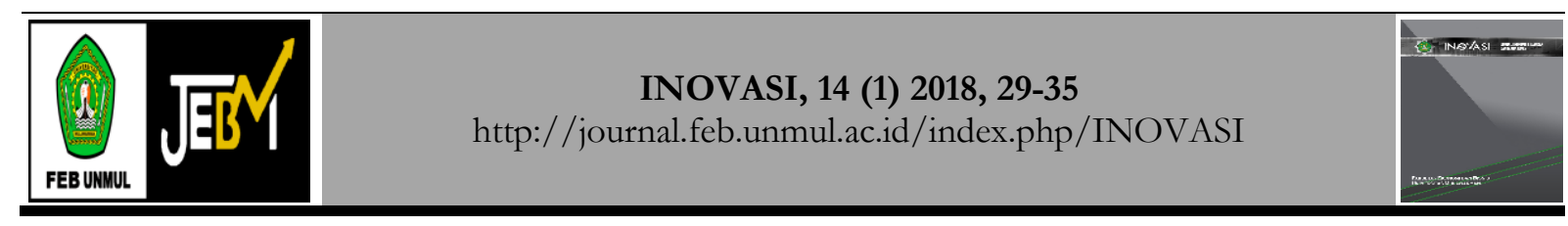

\title{
Faktor-faktor sosial ekonomi pada wanita yang menikah dini dalam mempengaruhi fertilitas
}

\author{
Sefti Normalasari ${ }^{1}$, Irwan Gani ${ }^{2}$, Siti Amalia ${ }^{3}$ \\ Fakultas Ekonomi dan Bisnis Universitas Mulawarman, Samarinda. \\ ${ }^{1}$ Email: sefti.normalasari@mhs.feb.unmul.ac.id \\ ${ }^{2}$ Emal: irwan.gani@feb.unmul.ac.id \\ ${ }^{3}$ Email: siti.amalia@feb.unmul.ac.id
}

\begin{abstract}
Abstrak
Tujuan dari penelitian ini adalah untuk membuktikan secara empiris Pengaruh Pendapatan, Pendidikan, Jumlah Anggota Keluarga dan Kustom \& Budaya terhadap tingkat kesuburan pada wanita yang menikah di awal Sungai Pinang Dalam Kota Samarinda. Alat analisis yang digunakan adalah Regresi Linier Berganda dengan menggunakan Dummy dengan bantuan program SPSS versi 23.0 for windows. Hasilnya menunjukkan bahwa pendapatan dan jumlah anggota keluarga memiliki pengaruh positif dan signifikan terhadap tingkat kesuburan pada wanita yang menikah di awal Sungai Pinang Dalam, Pendidikan memiliki pengaruh negatif dan signifikan terhadap tingkat kesuburan pada wanita yang menikah di awal Sungai Pinang Dalam dan Kustom \& Budaya Ada perbedaan tingkat kesuburan yang signifikan pada wanita yang menikah di awal Sungai Pinang Dalam Kota Samarinda.
\end{abstract}

Kata Kunci: Pendapatan; pendidikan; jumlah anggota keluarga; adat dan budaya; tingkat kesuburan

\section{Socioeconomic factors in women who are married early in affecting fertility}

\begin{abstract}
The purpose of this study was to prove empirically the Influence of Revenue, Education, Number of Family Members and Custom \& Culture on fertility rate in women who married early in Sungai Pinang Dalam Samarinda City. The analytical tool used is Multiple Linear Regression using Dummy with the help of program SPSS version 23.0 for windows. The results indicate that the income and Number of Family Members have a positive and significant effect on fertility rate in women who married early in Sungai Pinang Dalam, Education has a negative and significant effect on fertility rate in women who married early in Sungai Pinang Dalam and Custom \& Culture There was a significant difference in fertility rates in women who married early in Sungai Pinang Dalam Samarinda City.
\end{abstract}

Keywords: Revenue; education; number of family members; custom and culture; fertility rate 


\section{PENDAHULUAN}

Salah satu masalah kependudukan yaitu jumlah penduduk yang besar dan distribusi yang tidak merata. Hal itu diikuti dengan masalah lain yang lebih spesifik, yaitu angka fertilitas yang relatif tinggi. Kondisi ini dianggap tidak menguntungkan dari sisi pembangunan ekonomi, hal itu diperkuat dengan kenyataan bahwa kualitas penduduk masih rendah, sehingga penduduk lebih diposisikan sebagai beban dari pada modal pembangunan (Munir,1984:170).

Fertilitas sebagai istilah demografi diartikan sebagai hasil reproduksi yang nyata dari seorang wanita atau kelompok wanita, dengan kata lain fertilitas ini menyangkut banyaknya bayi yang lahir hidup. Fertilitas dipengaruhi dan ditentukan oleh dua faktor yaitu faktor demografi dan faktor non demografi. Faktor demografi antara lain umur, umur perkawinan pertama, lama perkawinan, paritas atau jumlah persalinan yang pernah dialami dan proporsi perkawinan, sedangkan faktor non demografi antara keadaan ekonomi penduduk, tingkat pendidikan, perbaikan status wanita, urbanisasi dan industrialisasi (BPS, 2013).

Tingkat fertilitas seorang wanita dipengaruhi oleh berbagai macam faktor, termasuk tingkat pendidikan, pekerjaan, pendapatan, persepsi nilai anak, kematian bayi/balita, unmeet need, dan umur kawin pertama (Yuniarti, dkk, 2013).

Sebuah studi mengenai prevalensi pernikahan usia dini dan efeknya terhadap fertilitas dan fertilitas kontrol pada wanita muda di India juga menyebutkan bahwa wanita yang umur kawin pertamanya $<18$ tahun cenderung memiliki tingkat fertilitas yang tinggi dibandingkan wanita yang menikah di usia dewasa $(27,1 \%$ dibanding $3,5 \%)$, di mana dalam studi tersebut fertilitas didefinisikan sebagai kelahiran tiga atau lebih anak dari seorang wanita. Menurut studi yang sama, 20,4\% wanita yang menikah di umur < 18 tahun telah memiliki anak di tahun pertama pernikahan sementara wanita yang menikah di umur dewasa dan memiliki anak di tahun pertama pernikahan sebesar $19,1 \%$ (Raj dkk, 2009).

Data United Nations International Children's Emergency Fund (UNICEF) pada tahun 2007 menunjukkan bahwa wanita yang menikah di bawah usia 18 tahun mencapai 34\%, dan Indonesia termasuk dalam lima besar Negara-negara yang presentase pernikahan dini tertinggi di dunia. Indonesia juga merupakan negara dengan presentase tertinggi kedua di ASEAN setelah Kamboja. Data SDKI 2012 menunjukkan masih terdapat sekitar 13\% remaja perempuan berusia 15-19 tahun yang telah menikah, separuh di antara mereka telah memiliki setidaknya satu anak pada rentang usia tersebut. Pada tingkat provinsi, Kalimantan Selatan menduduki peringkat pertama yang presentase pernikahan dininya (15-19 tahun) tinggi yaitu sebesar 9\%, disusul Jawa Barat sebesat 7,5\%, serta Kalimantan Timur dan Kalimantan Tengah dengan presentase masing-masing 7\% dan 6,5\% (BKKBN, 2012). Perkawinan di usia muda ini akan memberikan sumbangan terhadap tingginya kelahiran. Meskipun persentasenya relatif kecil, fenomena ini perlu mendapat perhatian karena cenderung banyak kasus perkawinan usia dini tidak tercatat dengan baik (underreported). Selain itu, masih terjadi perkawinan di usia kurang dari 14 tahun, bahkan terjadi di daerah perkotaan yang umumnya akses dan informasinya lebih banyak dan mudah diperoleh (Wahyuni dan Rahmadewi, 2011).

Dampak dari pernikahan usia dini dari segi sosial ekonomi yaitu pernikahan dini dapat menyebabkan meningkatnya angka kematian yang terjadi karena melahirkan di usia muda, rendahnya kualitas SDM akibat dari terputusnya sekolah, kemiskinan, serta meningkatnya angka kelahiran yang mengakibatkan pertumbuhan penduduk yang pesat. Hal tersebut tentukan akan mempengaruhi pencapaian pemerintah dalam mewujudkan target pembangunan yang tercantum di dalam Millenium Develompment Goals (MDGs) 2015 (Sinta, 2009).

Pernikahan dini yang terjadi pada perempuan usia 15 tahun mempunyai masa reproduksi jauh lebih panjang dibanding mereka yang menikah di atas usia 25 tahun dimana masa reproduksi yang lama maka kemungkinan untuk melahirkan semakin besar sehingga bisa saja mempunyai anak lebih dari dua bahkan lebih dari lima. Jika pernikahan diadakan pada umur lanjut, maka fertilitas potensil yang telah dilalui tidak akan diperoleh kembali, sebaliknya apabila perkawinan diadakan pada umur muda setidak-tidaknya orang muda tersebut mempunyai keturunan sebelum mereka menutup usia. Maka dari itu sudah jelas bahwa pernikahan dini dapat memacu tingkat fertilitas yang tinggi.

Jumlah penduduk yang terus meningkat akan menghambat pertumbuhan ekonomi karena terlalu banyaknya dana yang harus diinvestasikan untuk memenuhi kebutuhan-kebutuhan pokok dan untuk 
ditanamkan pada infrastruktur sehingga akan menurunkan peluang penanaman modal dalam bidang lain yang lebih produktif. Dari segi ekonomi, jumlah penduduk yang besar akan menyebabkan tingginya angka pengangguran, dan kemiskinan apabila tidak diimbangi dengan tersedianya lapangan pekerjaan yang memadai. Selain itu penduduk yang banyak berpotensi meningkatkan angka kriminalitas dan perusakan lingkungan (Pratiwi, 2014).

Angka fertilitas yang tinggi di dalam suatu Negara akan menimbulkan banyak dampak bersifat negative, salah satunya adalah terjadinya ledakan penduduk.

Tabel 1. Penduduk, KK dan Fertilitas Kelurahan

\begin{tabular}{clll}
\multicolumn{4}{c}{ Sungai Pinang Dalam Tahun } \\
\hline Tahun & Jum.Pddk & KK & Fertilitas \\
\hline 2012 & 40310 & 10548 & 293 \\
2013 & 39838 & 10812 & 368 \\
2014 & 39428 & 11428 & 556 \\
\hline \multicolumn{4}{l}{ Sumber: Data Demografi Kel.SPD Tahun 2012-2014 }
\end{tabular}

Berdasarkan tabel diatas Jumlah penduduk Kelurahan Sungai Pinang dari tahun 2012 sampe 2014 mengalami penurunan, namun berbeda dengan jumlah RT yang terus meningkat setiap tahun. Walaupun jumlah penduduk di Kelurahan Sungai Pinang Dalam terus menurun akan tetapi jumlah rumah tangga terus mengalami kenaikan, hal ini menandakan bahwa setiap tahunnya penduduk yang menikah semakin banyak. Begitupula dengan jumlah fertilitas yang setiap tahunnya terus meningkat. Artinya bahwa program pemerintah dalam menangani fertilitas di Kelurahan Sungai Pinang Dalam tidak sepenuhnya berjalan dengan baik karena dari penduduknya sendiri masih belum menyadari pentingnya mengikuti program yang sudah di terapkan oleh pemerintah setempat. Terbukti dari tahun ketahun tingkat fertilitas semakin tinggi (Sumber : Monografi Kelurahan Sungai Pinang Dalam).

\section{Kajian Pustaka}

\section{Kependudukan}

Penduduk merupakan semua orang yang berdomisili di wilayah geografis indonesia selama enam bulan atau lebih atau mereka yang berdomisili kurang dari enam bulan tetapi bertujuan menetap. Pertumbuhan penduduk diakibatkan oleh tiga komponen yaitu: fertilitas, mortalitas dan migrasi. Salah satu faktor yang menentukan keberhasilan pembangunan adalah pelaksanaan pembangunan itu sendiri. Salah satu faktor yang menentukan keberhasilan pembangunan adalah pelaksanaan pembangunan itu sendiri, namun demikian penduduk indonesia menurut strukturnya berbeda dengan struktur negara yang lebih maju. Struktur penduduk Indonesia dikatakan masih muda atau sebagian besar penduduk Indonesia berusia muda. Mengingat hanya orang dewasa saja yang bisa bekerja, dan pada umumnya dalam suatu keluarga hanya ada satu yang bekerja berarti bahwa untuk setiap orang yang bekerja harus menanggung beban hidup dari anggota keluarga dari yang cukup besar. Makin banyak orang yang harus ditanggung oleh setiap orang yang bekerja makin rendah kesejahteraan penduduk. (Subagiarta. 2006)

Teori ekonomi kependudukan yang dikemukakan oleh beberapa ahli menjelaskan bahwa faktorfaktor yang menentukan jumlah kelahiran anak yang diinginkan per-keluarga diantaranya adalah berapa banyak kelahiran yang dapat dipertahankan hidup (survive). Tekanan yang utama adalah cara bertingkah laku itu sesuai dengan yang dikehendaki apabila orang melaksanakan perhitunganperhitungan kasar mengenai jumlah kelahiran anak yang diinginkannya. Perhitungan-perhitungan demikian itu tergantung pada keseimbangan antara kepuasan atau kegunaan (utility) yang diperoleh dari biaya tambahan kelahiran seorang anak, baik berupa keuangan maupun psikis.

\section{Fertilitas}

Fertilitas merupakan hasil reproduksi nyata dari seorang atau sekelompok wanita, sedangkan dalam bidang demografi Fertilitas ialah suatu istilah yang digunakan untuk menggambarkan jumlah anak yang benar-benar dilahirkan dalam keadaan hidup. Besar kecilnya jumlah kelahiran dalam suatu penduduk, tergantung pada beberapa faktor misalnya struktur umur, tingkat pendidikan, umur pada waktu kawin pertama, banyaknya perkawinan, status pekerjaan wanita, penggunaan alat kontrasepsi dan pendapatan atau kekayaan. Pola fertilitas dapat dibedakan menjadi dua yaitu kelompok individu yang merasa tidak memperoleh keuntungan ekonomi, karena membatasi kelahiran dan kelompok 
individu yang merasa mendapatkan keuntungan ekonomis karena membatasi kelahiran. Perubahan dari pola pertama ke pola kedua disebabkan oleh adanya perubahan sosial ekonomi.

Alat Analisis

Alat analisis yang digunakan adalah regresi linier berganda, dengan rumus sebagai berikut:

$Y=\alpha+\beta_{1} X_{1}+\beta_{2} X_{2}+\beta_{3} X_{3}+\beta_{4} D$

$+\varepsilon$

Dimana:

$Y \quad=$ Fertilitas

$X_{1} \quad=$ Pendapatan

$X_{2} \quad=$ Pendidikan

$X_{3} \quad=$ Jumlah Anggota Keluarga

$D \quad=$ Dummy variabel untuk Adat \& Budaya

$1=$ di jodohkan

$0 \quad=$ tidak di jodohkan

$\alpha \quad=$ konstanta

$\beta_{1}, \beta_{2}, \beta_{3}, \beta_{4}=$ koefesien regresi

$\mathrm{e}=$ error atau variabel pengganggu (variabel yang tidak diteliti)

Persamaan koefisien $\mathrm{D}=1$ (di jodohkan)

$Y=\left(\alpha+\beta_{4} D\right)+\beta_{1} X_{1}+\beta_{2} X_{2}+$

$\beta_{3} X_{3}$

Persamaan koefisien $\mathrm{D}=0$ (tidak di jodohkan)

$Y=\alpha+\beta_{1} X_{1}+\beta_{2} X_{2}+\beta_{3} X_{3}$

Sebelum dilakukannya pengujian hipotesis ( $\mathrm{Uji} R, R^{2}, F$, dan $t$ ) terlebih dahulu dilakukan pengujian asumsi klasik berupa uji Normalitas, Multikolinearitas, Heteroskedastisitas dan uji Autokorelasi.

\section{HASIL DAN PEMBAHASAN}

Pengaruh variabel pendapatan $\left(\mathrm{X}_{1}\right)$, Pendidikan $\left(\mathrm{X}_{2}\right)$, Jumlah Anggota Keluarga $\left(\mathrm{X}_{3}\right)$ dan Adat \& Budaya (D) terhadap Fertilitas (Y) pada penelitian terhadap 37 wanita yang menikah dini di Kelurahan Sungai Pinang Dalam, diperoleh persamaan sebagai berikut:

\begin{tabular}{|c|c|c|c|c|}
\hline & $\overline{X_{1}}$ & $X_{2}$ & $X_{3}$ & $\bar{D}$ \\
\hline $\mathrm{SE}=$ & 1,268 & $-0,136$ & 0,124 & $-0,321$ \\
\hline Thit $=$ & 2,048 & $-3,496$ & 2,366 & $-2,357$ \\
\hline $\operatorname{Sig}=$ & 0,049 & 0,001 & 0,024 & 0,025 \\
\hline$F_{\text {hit }}=$ & 23,364 & $\operatorname{Sig}=$ & 0,000 & \\
\hline $\mathrm{R}=$ & 0,863 & $\mathrm{R}^{2}=$ & 0,745 & \\
\hline
\end{tabular}

\section{Uji Asumsi Klasik}

Uji normalitas mendeskripsikan kenormalan dari suatu distribusi data. Uji KolmogorovSmirnov dengan perolehan nilai Asymp. Sig (2-tailed) sebesar 0,200 $>0,05$ sehingga data terdistribusi secara normal. 


\begin{tabular}{lllllll}
\hline \multicolumn{7}{c}{ Tabel 2. Tests of Normality } \\
& \multicolumn{3}{c}{ Kolmogorov-Smirnov } & \multicolumn{3}{c}{ Shapiro-Wilk } \\
\cline { 2 - 7 } & Statistic & df & Sig. & Statistic & df & Sig. \\
\hline Unstandardized & .116 & 37 & $.200^{*}$ & .942 & 37 & .053 \\
Residual &. & & & & & \\
*. This is a lower bound of the true significance. & & & \\
a. Lilliefors Significance Correction & & & & \\
\hline Sumber : Hasil Perhitungan SPSS
\end{tabular}

Multikolinearitas dilakukan guna "membuktikan" ada tidaknya korelasi yang sempurna antar variabel bebas dalam model regresi. Kriteria ujinya, jika nilai tolerance $>10 \%$ atau Variance Inflation Factor (VIF) < 10 maka dinyatakan tidak ada gejala multikolinieritas. Dari hasil olahan menunjukkan bahwa tidak ada multikolinearitas pada semua variabel bebas.

Tabel 3. Coefficients ${ }^{\mathrm{a}}$

\begin{tabular}{llll}
\hline \multirow{2}{*}{ Model } & \multicolumn{2}{c}{$\begin{array}{c}\text { Collinearity } \\
\text { Statistics }\end{array}$} \\
\cline { 2 - 3 } & Tolerance & VIF \\
\hline 1 & (Constant) & .222 & 4.508 \\
& Lg_X1 & .874 & 1.144 \\
& Pendidikan (X2) & .236 & 4.236 \\
\hline \multicolumn{2}{l}{ Jumlah Anggota Keluarga (X3) } \\
\hline
\end{tabular}

a. Dependent Variable: Fertilitas (Y)

Sumber: Hasil Perhitungan SPSS

Uji Heteroskedastisitas dilakukan untuk "membuktikan" adanya perbedaan varian antar pengamatan dalam model regresi. Dari hasil di ketahui bahwa nilai signifikansi uji t ketiga variabel independen dengan Absolut Residual (ABS_RES) lebih dari 0.05. Sehingga dapat disimpulkan bahwa model regresi tidak ada masalah heteroskedastisitas.

Tabel 4. Coefficients ${ }^{\mathrm{a}}$

\begin{tabular}{llll}
\hline Model & $\mathrm{t}$ & $\mathrm{S}$ Sig. \\
\hline $1 \quad$ (Constant) & 596 & .555 \\
& Lg_X1 & .547 & .588 \\
& Pendidikan (X2) & 1.663 & .106 \\
& Jumlah Anggota Keluarga (X3) & -.733 & .469 \\
\hline
\end{tabular}

a. Dependent Variable: ABS_RES

Sumber: Hasil perhitungan SPSS

Hasil perhitungan data yang diperoleh nilai DW (Durbin-Watson) sebesar 2.074. Tabel DW (Durbin-Watson) dengan tingkat signifikan 0,05 dengan jumlah data $(\mathrm{n})=37$ serta $\mathrm{K}=3$ diperoleh nilai dL 1,307. nilai dU 1,655. Maka 4-dU=2,345 dan 4-dL=2,693. Karena nilai DW (2.194) berada pada daerah antara dU dan 4-dU yakni $1,655<2.074<2,345$, maka $H_{0}$ diterima. Jadi, tidak terjadi autokorelasi pada model regresi.

Hasil uji F, Fhit $>$ Ftabel yaitu $23.364>2,901$ serta sig. uji $\mathrm{F}<0,05(0,000<0,05)$ maka H0 ditolak dan H1 diterima. Hal ini berarti pendapatan, pendidikan, jumlah anggota keluarga dan adat \& budaya secara serempak berpengaruh signifikan terhadap fertilitas di Kelurahan Sungai Pinang Dalam.

Hasil perhitungan nilai koefisien korelasi $\left({ }^{R}\right)$ sebesar $0,863(R>0,5)$ yang berarti ada hubungan yang sangat kuat antara pendapatan, pendidikan, jumlah anggota keluarga dan adat \& budaya terhadap fertilitas di Kelurahan Sungai Pinang Dalam. Sedangkan nilai koefisien determinasi $\left({ }^{2}\right)$ sebesar 0,745 menunjukkan pengaruh pendapatan, pendidikan, jumlah anggota keluarga dan adat $\&$ budaya terhadap fertilitas di Kelurahan Sungai Pinang Dalam sebesar 74,50\%, sedangkan sisanya $25,50 \%$ di pengaruhi oleh variabel lain yang tidak di teliti. 
Nilai thitung variabel pendapatan sebesar 2,048 dengan signifikansi $0,049<\alpha=0,05$ artinya pendapatan (X1) pada wanita yang menikah dini berpengaruh signifikan terhadap fertilitas (Y) di Kelurahan Sungai Pinang Dalam. Hasil penelitian ini sesuai dengan penelitian yang dilakukan oleh Mirah (2013) yang mengatakan semakin besar penghasilan keluarga, maka akan berpengaruh terhadap besarnya jumlah keluarga dan pola konsumsi, karena terdorong oleh tersedianya barang-barang produk baru sehingga berdampak pada pendapatan suatu keluarga. Hal ini juga sesuai dengan penelitian yang dilakukan oleh Adi (2013) yang mengatakan bertambahnya jumlah anggota keluarga tentu saja akan menambah jumlah kebutuhan dalam memenuhi keperluan anggota keluarga.

Nilai $t_{\text {hitung }}$ variabel Pendidikan -3,496 dengan signifikansi $0,001<\alpha=0,05$ artinya pendidikan (X2) pada wanita yang menikah dini berpengaruh signifikan terhadap fertilitas (Y) di Kelurahan Sungai Pinang Dalam. Hasil penelitian ini sesuai dengan penelitian yang dilakukan oleh lakukan oleh Utina (2014) yang mengatakan pendidikan berpengaruh terhadap tinggi rendahnya fertilitas karna akan mempengaruhi pola fikir dan orientasi karir seseorang, selain itu pendidikan juga berpengaruh terhadap pengetahuan mengenai usia yang tepat untuk merencanakan kehamilan dan pentingnya ber-KB.

Nilai $t_{\text {hitung }}$ variabel Jumlah Anggota Keluarga 2,366 dengan signifikansi $0,024<\alpha=0,05$ artinya jumlah anggota keluarga (X3) pada wanita yang menikah dini berpengaruh signifikan terhadap fertilitas (Y) di Kelurahan Sungai Pinang Dalam. Hasil penelitian ini sesuai dengan penelitian yang dilakukan oleh oleh Ismail (2016) yang mengatakan Jumlah anggota keluarga menjadi faktor yang mempengaruhi tingkat fertilitas di suatu daerah. Keluarga yang memiliki banyak anak akan menyebabkan meningkatnya laju pertumbuhan penduduk, dengan tingginya laju pertumbuhan penduduk maka akan meningkatkan tingkat fertilitas. Oleh karena itu semakin banyak anggota keluarga maka akan menyebabkan meningkatnya tingkat fertilitas di suatu daerah.

Nilai thitung variabel Adat \& Budaya -2,357 dengan signifikansi $0.025<\alpha=0,05$ artinya adat \& budaya (D) pada wanita yang menikah dini terdapat perbedaan terhadap fertilitas (Y) di Kelurahan Sungai Pinang Dalam. Hasil penelitian ini sesuai dengan penelitian yang dilakukan oleh Wirosuhadjo (2000) Semakin muda seseorang melakukan perkawinan makin panjang masa reproduksinya, maka dapat disimpulkan makin muda seseorang untuk melangsungkan perkawinannya makin banyak pula anak yang dilahirkan. Kehamilan di usia muda berpengaruh secara nyata terhadap prilaku demografi terutama tentang jumlah dan pertambahan penduduk melalui fertilitas.

\section{SIMPULAN} berikut:

Berdasarkan hasil analisis data yang telah diuraikan, maka diperoleh kesimpulan sebagai

Faktor pendapatan dan jumlah anggota keluarga pada wanita yang menikah dini berpengaruh positif dan signifikan terhadap fertilitas di Kelurahan Sungai Pinang Dalam.

Faktor pendidikan pada wanita yang menikah dini berpengaruh negatif dan signifikan terhadap fertilitas di Kelurahan Sungai Pinang Dalam.

Faktor adat dan budaya pada wanita yang menikah dini terdapat perbedaan yang signifikan terhadap fertilitas di Kelurahan Sungai Pinang Dalam.

\section{DAFTAR PUSTAKA}

Al-Gifari, A. 2002. Pernikaan Dini Dilema Generasi Ekstravaganza. Bandung : Mujahid Press.

Apriansyah, 2015. “Analisis Tingkat Kelahiran (Fertilitas) di Kota Samarinda”. Samarinda, FE Unmul. 2015

Bambang Prasetyo, Lina Miftahul Jannah. "Metode Penelitian Kuantitatif” (Jakarta: Raja Grafindo Persada.2005) h: 42

Davis, Kingsley \& Judith Blake.1976. "Struktur Sosial dan Fertilitas". Lembaga Kependudukan Universitas Gadjah Mada : Yogyakarta

Fajrin, 2015. "Pengaruh Pendidikan dan Pendapatan Terhadap Fertilitas di Kelurahan Air Putih". Samarinda, FE Unmul. 2015 
Fitriasari, 2015. "Pengaruh Pendidikan Ibu, Pendapatan dan Jumlah Anggota Keluarga Terhadap Keputusan Ibu Bekerja di Kelurahan Air Putih”. Samarinda, FE Unmul. 2015

Gani, Irwan, dan Amalia, Siti. 2015. "Alat Analisis Data: Aplikasi Statistik untuk Penelitian Bidang Ekonomi dan Sosial. Yogyakarta: Penerbit ANDI

G.S Becker. 1992. "Fertility and Pensions". Journal of population economics. Kependudukan Universitas Gadjah Mada : Yogyakarta

Hartanto, 2012. "Hubungan Pola Asuh Orang Tua Dengan Kejadian Pernikahan Usia Dini di Desa Jambul Kidul, Ceper, Klaten". Jurnal Biometrika dan Kependudukan, Vol. 5, No.2 September 2012, hal 70-86

Irawan, 2015. "Pengaruh Pendapatan dan Pendidikan Terhadap Jumlah Anak di Kecamatan Sungai Pinang, Samarinda". Samarinda, FE Unmul. 2015

Ismail, 2016. "Faktor yang Mempengaruhi Fertilitas di Kelurahan Tanjung Raya Kecamatan Kedamaian Kota Bandar Lampung”. Bandar Lampung, FE Unlam. 2016

Munir, Rozy. 1984. Teknik Demografi. Radar Jaya offset : Jakarta

Movementi S. 2013. BKKBN Dorong Kenaikan Batas Usia Pernikahan. http://www.tempo.co/read/news/2013/02/27/173464028/BKKBN-Dorong-Kenaikan-BatasUsia-Pernikahan. Diakses tanggal 6 Desember 2015.

Nad. 2014. Beragam Efek Buruk Pernikahan Dini. http//www.beritasatu.com/gaya-hidup/177423beragam-efek-buruk- pernikahan dini.html. Diakses tanggal 6 Desember 2015.

Naibaho, 2010. "Faktor-Faktor Yang Mempengaruhi Pernikahan Usia Muda (Studi Kasus di Dusun IX Seroja Pasar VII Tembung Kecamatan Percut Sei Tuan Kabupaten Deli Serdang)". Jakarta, FISIP UI, 2010.

Nandang, dkk. 2009. "Pengaruh Faktor Sosial, Demografi Terhadap Jumlah Anak Yang Pernah Dilahirkan Hidup Di Kabupaten Madiun”. Surabaya, Universitas Negeri Surabaya, 2009.

Nugraheni. 2007. "Faktor Yang Mempengaruhi Fertilitas Di Desa Kandangtepus Kecamatan Senduro Kabupaten Lumajang”. Jember, Universitas Negeri Jember, 2007.

Nurhajati, dkk, 2013. "Pengaruh Faktor Sosial Ekonomi terhadap Usia Kawin Pertama Wanita di Kecamatan Bangli”. E-Jurnal EP Unud, Vol. 3, No. 3 Maret 2013.

Pamungkas, 2006. "Perkawinan Usia Muda: Jumlah Anak dan Fertilitas". Surabaya, FISIP Universitas Airlangga, 2006.

Rafidah, Emilia, Wahyuni. 2009. Faktor-faktor yang Berhubungan dengan Pernikahan Usia Dini di Kabupaten Purworejo, Jawa Tengah. Berita Kedokteran Masyarakat, Vol. 25, No. 2, Juni 2009 , hal 51-58.

Rohmat, 2009. "Studi Kasus Kebiasaan Pernikahan Usia Dini Pada Masyarakat Kecamatan Sanggalangi Kabupaten Tana Toraja". Jurnal MKMI, Vol. 5 No. 4, Oktober 2009, hal 89-94.

Sinta. 2009. "Pernikahan Usia Dini dan Permasalahannya". Jurnal FK Unipad, Vol.11, No. 2, Agustus 2009. 